\title{
Strategy and Software Application of Fresh Produce Package Design to Attain Optimal Modified Atmosphere
}

\author{
Dong Sun Lee, Yun Hee Jo, Min-Ji Kwon, and Duck Soon An \\ Department of Food Science and Biotechnology, Kyungnam University, 7 Kyungnamdaehak-ro, Masanhappo-gu, \\ Changwon 631-701, Republic of Korea \\ Correspondence should be addressed to Dong Sun Lee; dongsun@kyungnam.ac.kr
}

Received 17 March 2014; Accepted 16 June 2014; Published 6 July 2014

Academic Editor: Li-xin Lu

Copyright (C) 2014 Dong Sun Lee et al. This is an open access article distributed under the Creative Commons Attribution License, which permits unrestricted use, distribution, and reproduction in any medium, provided the original work is properly cited.

\begin{abstract}
Modified atmosphere packaging of fresh produce relies on the attainment of desired gas concentration inside the package resulting from product respiration and package's gas transfer. Systematic package design method to achieve the target modified atmosphere was developed and constructed as software in terms of selecting the most appropriate film, microperforations, and/or $\mathrm{CO}_{2}$ scavenger. It incorporates modeling and/or database construction on the produce respiration, gas transfer across the plastic film and microperforation, and $\mathrm{CO}_{2}$ absorption by the scavenger. The optimization algorithm first selects the packaging film and/or microperforations to have the target $\mathrm{O}_{2}$ concentration in response to the respiration and then tunes the $\mathrm{CO}_{2}$ concentration by $\mathrm{CO}_{2}$ absorber when it goes above its tolerance limit. The optimization method tested for green pepper, strawberry, and king oyster mushroom packages was shown to be effective to design the package and the results obtained were consistent with literature work and experimental atmosphere.
\end{abstract}

\section{Introduction}

Modified atmosphere packaging (MAP) of fresh produce is based on attaining the modified atmosphere (MA) resulting from contributions of produce respiration and plastic film gas permeation. For effective preservation of the fresh produce, desired or optimal modified atmosphere of reduced $\mathrm{O}_{2}$ and elevated $\mathrm{CO}_{2}$ concentrations specific for the commodity should be created and maintained. Control variables to attain the desired atmosphere in MAP design are type of packaging film, its area and thickness, presence and number of microperforations, and so forth, for the given pack size. Systematic way of MAP design has been implemented and is available in Internet web-based software for convenient and versatile design application to a wide variety of commodities and conditions [1-3]. The design tools have been built based on the databases of fresh produce respiration and plastic film gas permeability. While the currently available software can present the optimized package design consisting of plastic film condition (type and thickness) and perforation conditions if required, there is still a need for incorporating other options such as active packaging attachment [4].
Inclusion of carbon dioxide scavenger can help to ease the package optimization and widen the available MAP design window by attaining the desired MA without invading the injurious $\mathrm{CO}_{2}$ level [5]. Therefore, augmentation of MAP design scheme with $\mathrm{CO}_{2}$ scavenging has been tried in this study. Specific objectives of this study are to build and test a comprehensive fresh produce MAP design platform applicable to a wide variety of commodities and storage conditions.

\section{Algorithm for Optimized Package Design}

2.1. Model of Design Package. As the designable package model, modified atmosphere package of gas-permeable plastic tray or bag was conceptualized to be potentially appended with perforation or $\mathrm{CO}_{2}$ absorber (Figure 1). It was assumed that the package stays or is stored at constant temperature and respiration rate of fresh produce depends on the atmosphere surrounding the produce. Parameters of uncompetitive respiration model (1) describing the produce respiration rate [6] have been compiled as a database for many commodities and 


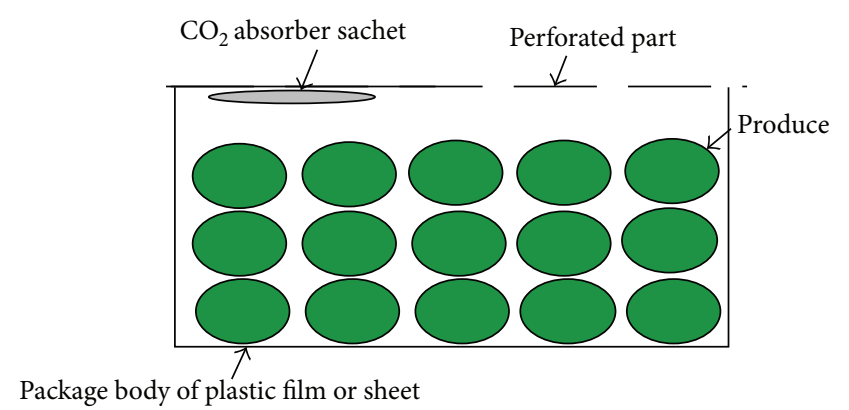

FIGURE 1: Fresh produce package structure to be optimized.

products, which is ready for being called from the design program. Thus, the respiration rate is given as:

$$
R_{\mathrm{O}_{2}} \text { or } R_{\mathrm{CO}_{2}}=\frac{V_{m} p_{\mathrm{O}_{2}}}{K_{m}+\left(1+p_{\mathrm{CO}_{2}} / K_{i}\right) p_{\mathrm{O}_{2}}},
$$

where $R_{\mathrm{O}_{2}}$ is the respiration rate of $\mathrm{O}_{2}$ consumption $\left(\mathrm{mol} \mathrm{kg}{ }^{-1} \mathrm{~h}^{-1}\right) ; R_{\mathrm{CO}_{2}}$ is the respiration rate of $\mathrm{CO}_{2}$ production $\left(\mathrm{mol} \mathrm{kg}{ }^{-1} \mathrm{~h}^{-1}\right) ; p_{\mathrm{O}_{2}}$ and $p_{\mathrm{CO}_{2}}$ are the respective partial pressures of $\mathrm{O}_{2}$ and $\mathrm{CO}_{2}(\mathrm{~Pa}) ; V_{m}, K_{m}$, and $K_{i}$ are the parameters.

Plastic gas permeability compiled from literatures or experimental measurements has also been established as a database to be called from the program.

Produce respiration and plastic film gas permeability at temperature other than the listed one can be supplied to the design program application by using Arrhenius equation [7, 8]:

$$
\begin{aligned}
& R_{i, T}=R_{i, T_{o}} \exp \left(\frac{E_{a}}{R} \cdot\left(\frac{1}{T_{o}}-\frac{1}{T}\right)\right), \\
& \bar{P}_{i, T}=\bar{P}_{i, T_{o}} \exp \left(\frac{E_{a}}{R} \cdot\left(\frac{1}{T_{o}}-\frac{1}{T}\right)\right),
\end{aligned}
$$

where $R_{i, T}$ and $R_{i, T_{o}}$ are the respective respiration rates at temperatures $T(\mathrm{~K})$ and $T_{o}(\mathrm{~K}) ; \bar{P}_{i, T}$ and $\bar{P}_{i, T_{o}}$ are the respective gas permeabilities ( $\mathrm{mol} \mathrm{mm} \mathrm{m}{ }^{-2} \mathrm{~h}^{-1} \mathrm{~Pa}^{-1}$ ) at temperatures $T(\mathrm{~K})$ and $T_{o}(\mathrm{~K}) ; E_{a}$ means the activation energy $\left(\mathrm{J} \mathrm{mol}^{-1}\right)$ corresponding to temperature dependence of respiration or gas permeation; $R$ is universal gas constant $\left(8.314 \mathrm{~J} \mathrm{~K}^{-1} \mathrm{~mol}^{-1}\right)$; the subscript $i$ refers to $\mathrm{O}_{2}$ or $\mathrm{CO}_{2}$ gas.

2.2. Mass Balances of Gases on the Produce Package. As a basis for designing fresh produce MAP, mass balance equations on the package with $\mathrm{CO}_{2}$ absorber incorporated have been set up:

$$
\begin{aligned}
\frac{d n_{\mathrm{O}_{2}}}{d t}= & \frac{N D_{\mathrm{O}_{2}} A\left(0.21 p_{a}-p_{\mathrm{O}_{2}}\right)}{L+\delta}\left(\frac{1}{R T}\right) \\
& +\frac{\bar{P}_{\mathrm{O}_{2}} S\left(0.21 p_{a}-p_{\mathrm{O}_{2}}\right)}{L}-W R_{\mathrm{O}_{2}},
\end{aligned}
$$

$$
\begin{aligned}
\frac{d n_{\mathrm{CO}_{2}}}{d t}= & \frac{N D_{\mathrm{CO}_{2}} A\left(0.00-p_{\mathrm{CO}_{2}}\right)}{L+\delta}\left(\frac{1}{R T}\right) \\
& +\frac{\bar{P}_{\mathrm{CO}_{2}} S\left(0.00-p_{\mathrm{CO}_{2}}\right)}{L} \\
& +W R_{\mathrm{CO}_{2}}+\frac{\bar{P}_{\mathrm{CO}_{2}, S} S_{s}\left(0.00-p_{\mathrm{CO}_{2}}\right)}{L_{s}}, \\
\frac{d n_{\mathrm{N}_{2}}}{d t}= & \frac{N D_{\mathrm{N}_{2}} A\left(0.78 p_{a}-p_{\mathrm{N}_{2}}\right)}{L+\delta}\left(\frac{1}{R T}\right) \\
& +\frac{\bar{P}_{\mathrm{N}_{2}} S\left(0.78 p_{a}-p_{\mathrm{N}_{2}}\right)}{L},
\end{aligned}
$$

where $n_{\mathrm{O}_{2}}, n_{\mathrm{CO}_{2}}$, and $n_{\mathrm{N}_{2}}$ are the respective mole numbers in the container of $\mathrm{O}_{2}, \mathrm{CO}_{2}$, and $\mathrm{N}_{2}$ gases at time $t(\mathrm{~h}) ; D_{\mathrm{O}_{2}}$, $D_{\mathrm{CO}_{2}}$, and $D_{\mathrm{N}_{2}}$ are the respective diffusivities of $\mathrm{O}_{2}, \mathrm{CO}_{2}$, and $\mathrm{N}_{2}$ gases in air $\left(\mathrm{m}^{2} \mathrm{~h}^{-1}\right) ; p_{\mathrm{O}_{2}}, p_{\mathrm{CO}_{2}}$, and $p_{\mathrm{N}_{2}}$ are the respective partial pressures of $\mathrm{O}_{2}, \mathrm{CO}_{2}$, and $\mathrm{N}_{2}$ in the package and $p_{a}$ is normal atmospheric pressure $\left(1.013 \times 10^{5} \mathrm{~Pa}\right) ; \mathrm{N}$ is the number of perforations of diameter $d(\mathrm{~m})$ and cross-sectional area $A\left(\mathrm{~m}^{2}\right)$ on the package; $\delta$ is a correction term for gas diffusion resistance in the perforations (1.1d); $L$ and $S$ are the thickness $(\mathrm{mm})$ and surface area $\left(\mathrm{m}^{2}\right)$ of the plastic layer, respectively; $\bar{P}_{\mathrm{O}_{2}}, \bar{P}_{\mathrm{CO}_{2}}$, and $\bar{P}_{\mathrm{N}_{2}}$ are the respective gas permeabilities of the plastic layer against $\mathrm{O}_{2}, \mathrm{CO}_{2}$, and $\mathrm{N}_{2}\left(\mathrm{~mol} \mathrm{~mm} \mathrm{~m} \mathrm{~mm}^{-2} \mathrm{~h}^{-1} \mathrm{~Pa}^{-1}\right)$; $W$ is the produce weight $(\mathrm{kg}) ; \bar{P}_{\mathrm{CO}_{2}, S}$ is the $\mathrm{CO}_{2}$ permeability of the $\mathrm{CO}_{2}$ absorber sachet $\left(\mathrm{mol} \mathrm{mm} \mathrm{m} \mathrm{m}^{-2} \mathrm{~h}^{-1} \mathrm{~Pa}^{-1}\right) ; L_{s}$ and $S_{s}$ are the thickness $(\mathrm{mm})$ and surface area $\left(\mathrm{m}^{2}\right)$ of the $\mathrm{CO}_{2}$ absorber sachet, respectively. The first terms on the right side of (3)-(5) represent gas-phase diffusion through the perforations based on Fick's law. The second terms in (3)-(5) describe the diffusive gas permeation through the plastic layer, and the third terms in (3) and (4) indicate the respiration activity. The last term in (4) represents the $\mathrm{CO}_{2}$ permeation loss to $\mathrm{CO}_{2}$ absorbent sachet.

The above equations (3)-(5) have been used as the basis for design of MAP to attain the desired MA close to the optimal one. All the derivatives equal to zero $\left(d n_{\mathrm{O}_{2}} / d t=0\right.$, $d n_{\mathrm{CO}_{2}} / d t=0, d n_{\mathrm{N}_{2}} / d t=0$ ) can be used to deal with steady state, and negation of the first terms on right side of (3)(5) amounts to the nonperforated packaging conditions. The solution of simultaneous differential equations (3)-(5) can give the history of gas moles in the package, which can be converted using the Ideal Gas Law to partial pressures of $\mathrm{O}_{2}$, $\mathrm{CO}_{2}$, and $\mathrm{N}_{2}\left(p_{\mathrm{O}_{2}}, p_{\mathrm{CO}_{2}}\right.$, and $\left.p_{\mathrm{N}_{2}}\right)$ or to volumetric percentages under normal atmosphere package atmosphere.

2.3. Design Scheme to Attain the Desired MA at Steady State. The design application starts with receiving the input information on commodity, temperature, expected shelf life, package's physical condition (type, produce weight, dimension, permeable surface area, and preferred microperforation), and film and type of $\mathrm{CO}_{2}$ absorption sachet. Selection of commodity dictates optimal $\mathrm{MA}, \mathrm{CO}_{2}$ tolerance limit, and respiration parameters (Figure 2 ). Then the required permeance values $\left(\Phi_{\mathrm{O}_{2}}\right.$ as $\bar{P}_{\mathrm{O}_{2}} / L$ and $\Phi_{\mathrm{CO}_{2}}$ as $\left.\bar{P}_{\mathrm{CO}_{2}} / L\right)$ of 


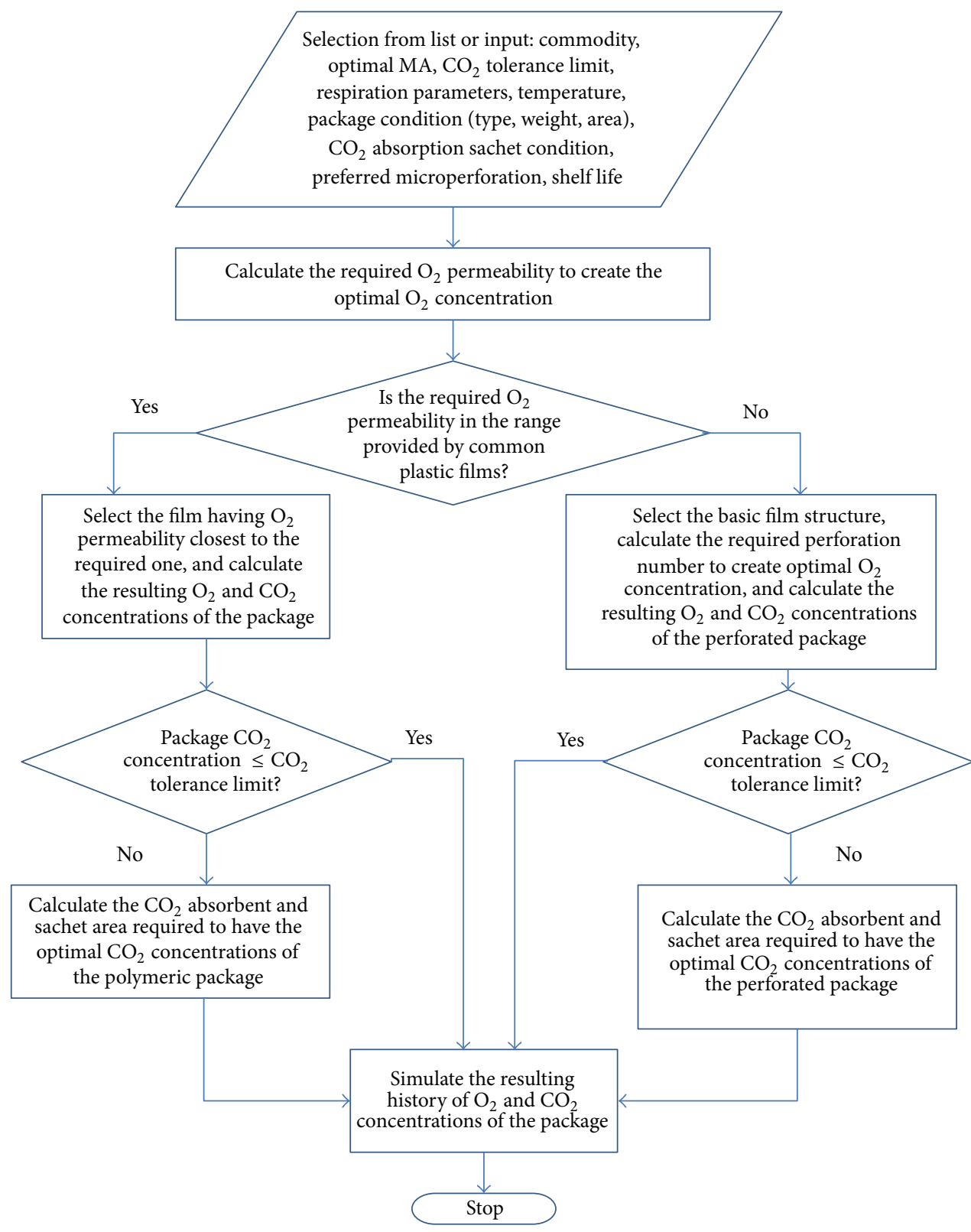

FIGURE 2: Flowchart for optimizing fresh produce MAP to give the target MA.

nonperforated package film to provide the optimal MA are calculated from the steady state assumption of (3) and (4) with $N=0$ and $S_{s}=0$ :

$$
\begin{gathered}
\Phi_{\mathrm{O}_{2}}=\frac{W R_{\mathrm{O}_{2}}}{S\left(0.21-\left[\mathrm{O}_{2}\right]_{o}\right) p_{a}}, \\
\Phi_{\mathrm{CO}_{2}}=\frac{W R_{\mathrm{CO}_{2}}}{S\left[\mathrm{CO}_{2}\right]_{o} p_{a}},
\end{gathered}
$$

where $\left[\mathrm{O}_{2}\right]_{o}$ and $\left[\mathrm{CO}_{2}\right]_{o}$ are optimal $\mathrm{O}_{2}$ and $\mathrm{CO}_{2}$ concentrations (atm or decimal), respectively. It is noted that $R_{\mathrm{O}_{2}}$ in (6) and $R_{\mathrm{CO}_{2}}$ in (7) are for the optimal MA.

Now it is examined whether commercially available films of usual thickness $\left(L_{n}, \mathrm{~mm}\right)$ can provide the required $\mathrm{O}_{2}$ permeance by calculating the correspondent $\mathrm{O}_{2}$ permeability, $\bar{P}_{\mathrm{O}_{2}, e}\left(\mathrm{~mol} \mathrm{~mm} \mathrm{~m} \mathrm{~m}^{-2} \mathrm{~h}^{-1} \mathrm{~Pa}^{-1}\right)$ :

$$
\bar{P}_{\mathrm{O}_{2}, e}=L_{n} \Phi_{\mathrm{O}_{2}} \text {. }
$$

If this $\bar{P}_{\mathrm{O}_{2}, e}$ can be covered by available plastic films (usually lower than the most permeable one such as linear low 
density polyethylene (LLDPE)), then the plastic film having the $\mathrm{O}_{2}$ permeability closest to $\bar{P}_{\mathrm{O}_{2}, e}$ is selected from the list in the gas permeability database. Unless this condition is not satisfied, we can conclude that perforation is needed for achieving the high gas transfer, which will be handled later separately as another conditional case of design. Now, the selected film is tailored in the thickness $(L)$ by using its $\mathrm{O}_{2}$ permeability $\left(\bar{P}_{\mathrm{O}_{2}, f}\right)$ :

$$
L=\frac{\bar{P}_{\mathrm{O}_{2}, f}}{\Phi_{\mathrm{O}_{2}}} .
$$

While the optimum $\mathrm{O}_{2}$ concentration $\left(\left[\mathrm{O}_{2}\right]_{0}\right)$ is ensured by the selection of the available film and its thickness $(L)$, the resultant $\mathrm{CO}_{2}$ concentration $\left(\left[\mathrm{CO}_{2}\right]_{p}\right)$ for this film condition (with $\mathrm{CO}_{2}$ permeability of $\bar{P}_{\mathrm{CO}_{2}, f}$ ) is newly calculated:

$$
\left[\mathrm{CO}_{2}\right]_{p}=\frac{W R_{\mathrm{CO}_{2}}}{S\left(\bar{P}_{\mathrm{CO}_{2}, f} / L\right) p_{a}} .
$$

If this $\mathrm{CO}_{2}$ concentration is above the $\mathrm{CO}_{2}$ tolerance limit, there is a potential risk of physiological injury due to high $\mathrm{CO}_{2}$ concentration. Thus, $\mathrm{CO}_{2}$ absorption is needed to lower the $\mathrm{CO}_{2}$ concentration down to the optimal level and its amount in moles $\left(n_{\mathrm{CO}_{2}, s}\right)$ can be assumed to be equal to the difference between respiratory $\mathrm{CO}_{2}$ production and $\mathrm{CO}_{2}$ permeation toward outside during the shelf life of $t_{s}(\mathrm{~h})$ :

$$
n_{\mathrm{CO}_{2}, a}=\left[W R_{\mathrm{CO}_{2}}-\frac{\bar{P}_{\mathrm{CO}_{2}, f} S\left(\left[\mathrm{CO}_{2}\right]_{o} p_{a}\right)}{L}\right] t_{s} .
$$

Because the $\mathrm{CO}_{2}$ absorption of the scavenger is achieved through permeation process of the sachet film, the surface area of sachet $\left(S_{s}, \mathrm{~m}^{2}\right)$ can be inferred from the steady state $\mathrm{CO}_{2}$ balance on the sachet:

$$
S_{s}=\frac{n_{\mathrm{CO}_{2}, a} L_{s}}{\bar{P}_{\mathrm{CO}_{2}, s}\left[\mathrm{CO}_{2}\right]_{o} p_{a} t_{s}} .
$$

From the steady state arrangement of (4) with foregoing relationship, the resultant $\mathrm{CO}_{2}$ concentration $\left(\left[\mathrm{CO}_{2}\right]_{p}\right)$ for the package with $\mathrm{CO}_{2}$ scavenger can be reached:

$$
\left[\mathrm{CO}_{2}\right]_{p}=\frac{W R_{\mathrm{CO}_{2}}}{\left\{S\left(\bar{P}_{\mathrm{CO}_{2}, f} / L\right)+S_{s}\left(\bar{P}_{\mathrm{CO}_{2}, s} / L_{s}\right)\right\} p_{a}} .
$$

If $\bar{P}_{\mathrm{O}_{2}, e}$ calculated by (8) is not enough to be provided by available permeable plastic films, the required number $(N)$ of basic perforations in diameter $d$ is obtained from the steady state case of (3):

$$
\begin{aligned}
& N=\left[\left(W R_{\mathrm{O}_{2}}-\frac{\bar{P}_{\mathrm{O}_{2}, f} S\left(0.21-\left[\mathrm{O}_{2}\right]_{e}\right) p_{a}}{L}\right)\right. \\
&\left.\times\left(\frac{L+1.1 d}{D_{\mathrm{O}_{2}}\left(\pi d^{2} / 4\right)\left(0.21-\left[\mathrm{O}_{2}\right]_{e}\right) p_{a}}\right)\right],
\end{aligned}
$$

where $\mathrm{O}_{2}$ permeability of basic plastic film is adopted as $\bar{P}_{\mathrm{O}_{2}, f}$.

With this number of perforations, the steady state $\mathrm{O}_{2}$ and $\mathrm{CO}_{2}$ concentrations $\left(\left[\mathrm{O}_{2}\right]_{p}\right.$ and $\left[\mathrm{CO}_{2}\right]_{p}$, resp. $)$ of basic film package (with $\mathrm{CO}_{2}$ permeability of $\bar{P}_{\mathrm{CO}_{2}, f}$ ) are stated anew from the steady state cases of (3) and (4) with $S_{s}=0$ (no scavenger):

$$
\begin{aligned}
{\left[\mathrm{O}_{2}\right]_{p}=} & 0.21 \\
& -\left(W R_{\mathrm{O}_{2}} \times\left(\frac{N D_{\mathrm{O}_{2}}\left(\pi d^{2} / 4\right)}{L+1.1 d}\left(\frac{p_{a}}{R T}\right)\right.\right. \\
& \left.\left.+\frac{\bar{P}_{\mathrm{O}_{2}, f} S p_{a}}{L}\right)^{-1}\right),
\end{aligned}
$$

$$
\begin{aligned}
{\left[\mathrm{CO}_{2}\right]_{p}=} & W R_{\mathrm{CO}_{2}} \\
& \times\left(\frac{N D_{\mathrm{CO}_{2}}\left(\pi d^{2} / 4\right)}{L+1.1 d}\left(\frac{p_{a}}{R T}\right)+\frac{\bar{P}_{\mathrm{CO}_{2}, f} S p_{a}}{L}\right)^{-1} .
\end{aligned}
$$

If the $\mathrm{CO}_{2}$ concentration from (16) is above the $\mathrm{CO}_{2}$ tolerance limit, $\mathrm{CO}_{2}$ scavenger is required to lower the $\mathrm{CO}_{2}$ concentration down to the optimal level $\left(\left[\mathrm{CO}_{2}\right]_{0}\right)$ and the scavenger amount can be obtained as respiratory $\mathrm{CO}_{2}$ production minus outward $\mathrm{CO}_{2}$ transfer through the perforation and film layer during the shelf life of $t_{s}(\mathrm{~h})$ :

$$
\begin{gathered}
n_{\mathrm{CO}_{2}, s}=\left(W R_{\mathrm{CO}_{2}}-\frac{N D_{\mathrm{CO}_{2}}\left(\pi d^{2} / 4\right)\left[\mathrm{CO}_{2}\right]_{o}}{L+1.1 d}\left(\frac{p_{a}}{R T}\right)\right. \\
\left.-\frac{\bar{P}_{\mathrm{CO}_{2}, f} S\left[\mathrm{CO}_{2}\right]_{o} p_{a}}{L}\right) t_{s} .
\end{gathered}
$$

Similar to the nonperforated case, surface area of $\mathrm{CO}_{2}$ scavenger can be obtained by the same equation (12) given above and the resulting $\mathrm{CO}_{2}$ concentration for the perforated package with the scavenger can be derived from the steady state condition of (4):

$$
\begin{aligned}
{\left[\mathrm{CO}_{2}\right]_{p}=} & W R_{\mathrm{CO}_{2}} \\
& \times\left(\frac{N D_{\mathrm{CO}_{2}}\left(\pi d^{2} / 4\right)}{L+1.1 d}\left(\frac{p_{a}}{R T}\right)\right. \\
& \left.+\frac{\bar{P}_{\mathrm{CO}_{2}, f} S p_{a}}{L}+\frac{\bar{P}_{\mathrm{CO}_{2}, s} S_{s} p_{a}}{L_{s}}\right)^{-1} .
\end{aligned}
$$

2.4. Estimation of Package Atmospheric Change under Designed Package Condition. Once all the package variables to give the desired MA close to optimal MA were decided based on the steady state analysis, the package atmospheric change as function of time can be estimated by the solution of simultaneous differential equations (3)-(5) as mentioned 
before. Runge-Kutta method with short time step was used for the solution in this study. For the simplified and stable solution, the condition of constant volume and normal atmospheric pressure was enforced at every time step of evolution with assuming simultaneous deflation of package atmosphere or infiltration of ambient air. Simplification for the solution stability of the mass balance equations on the perforated fresh package has been examined and discussed by Kwon et al. [11]. Usually nitrogen permeability of polymeric package film is much lower than that of oxygen or carbon dioxide and its partial pressure differential across the film is lower in the passive MA package, resulting in little change of nitrogen concentration, which tells limited influence of the $\mathrm{N}_{2}$ permeability on the package atmosphere. While there is sufficient information on $\mathrm{O}_{2}$ and $\mathrm{CO}_{2}$ permeabilities, there is not enough information on $\mathrm{N}_{2}$ permeability and thus $\mathrm{N}_{2}$ permeability was assumed as one-fifth of $\mathrm{O}_{2}$ permeability valid for common plastic films $[12,13]$. All the design scheme and atmosphere estimation were set up with a link to respiration and plastic permeability databases in an application of smart phone as a name, ProduceMAP. Comprehensive algorithm for the package optimization can be summarized as a flowchart in Figure 2.

\section{Application and Validation of the Developed Design Method by Using Case Studies}

Three commodities with different MA requirements were subjected to the developed design optimization program providing optimal conditions for their packages. The desired MA, respiration, and package dimension of the products supplied to the program as input information are given in Table 1.

3.1. Green Pepper Package. Green pepper is known to have low respiration activity and optimal MA of low $\mathrm{O}_{2}$ and low $\mathrm{CO}_{2}$ concentrations $[14,15]$ (Table 1 ). Thus, small permeable package unit has been reported by Lee et al. [9] to achieve the optimal MA by intact permeable film like low density polyethylene (LDPE). It also has moderately low tolerance to $\mathrm{CO}_{2}$ with its limit of $8.0 \%$. Submission of the same package unit of $110 \mathrm{~g}$ to ProduceMAP could provide the optimized solution giving an equilibrated MA close to the target (4\% $\mathrm{O}_{2}$ and $5 \% \mathrm{CO}_{2}$ concentrations) (Table 2 and Figure 3 ). The optimized bag package of $0.042 \mathrm{~mm}$ thick LDPE film was estimated to have equilibrated $\mathrm{MA}$ of $4.0 \% \mathrm{O}_{2}$ and $5.1 \%$ $\mathrm{CO}_{2}$ concentrations, which was closer to the target than that of a reported experimental package of $0.025 \mathrm{~mm}$ thick LDPE (5.1\% $\mathrm{O}_{2}$ and $3.3 \% \mathrm{CO}_{2}$ concentrations) [9]. The systematic optimization could select the film thickness better to create the optimal MA than the commonly used trial-and-error approach. The equilibrated $\mathrm{O}_{2}$ and $\mathrm{CO}_{2}$ concentrations with solution of differential equations (3)-(5) in Figure 3 (4.6 and $5.2 \%$, resp.) are a little different from those from (6) and (10) (4.0 and 5.1\%, resp.). This difference would have come from assuming the respiration as constant in the optimal MA and taking into consideration only $\mathrm{O}_{2}$ and $\mathrm{CO}_{2}$ balances, respectively, in steady state equations (6) and (10) without

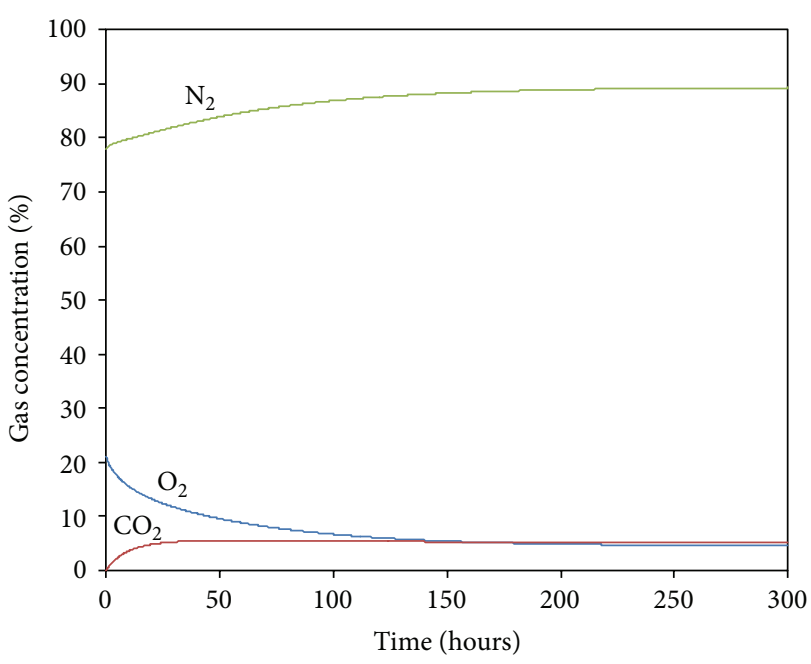

FIGURE 3: Optimal MA profile for green pepper package with requirements and design conditions in Tables 1 and 2 .

considering the nitrogen balance. However, this little difference less than $1 \%$ may be tolerated in practices of fresh produce MAP design. It is noted that the optimized package design for green pepper could be obtained without using perforation or $\mathrm{CO}_{2}$ absorption. Relatively green pepper's low respiration rate and location of optimal MA window at low $\mathrm{O}_{2}$ and low $\mathrm{CO}_{2}$ concentrations allowed the LDPE film having $\left(\bar{P}_{\mathrm{CO}_{2}} / \bar{P}_{\mathrm{O}_{2}}\right)$ ratio of $\approx 3.3$ to fit to the package of the target MA $[16,17]$.

3.2. Strawberry Package. Strawberry can tolerate high $\mathrm{CO}_{2}$ concentration and be benefited from storage under an MA of low $\mathrm{O}_{2}$ and high $\mathrm{CO}_{2}$ concentrations [15], which can be offered by microperforated package $[3,10,18]$. A package unit tried by Sousa-Gallagher and Mahajan [3] was optimized for the target of $8 \% \mathrm{O}_{2}$ and $18 \% \mathrm{CO}_{2}$ with $\mathrm{CO}_{2}$ tolerance limit of $20 \%$ by ProduceMAP program. The output of the design was a tray consisting of permeable oriented polypropylene (OPP) with two perforations of $0.25 \mathrm{~mm}$ resulting in an equilibrated MA of $9.3 \% \mathrm{O}_{2}$ and $17.5 \% \mathrm{CO}_{2}$ concentrations (Table 2). The solution of differential equations (3)-(5) for the optimal design resulted in the similar equilibrated MA (8.6 and 16.6\% for $\mathrm{O}_{2}$ and $\mathrm{CO}_{2}$ concentrations, resp., in Figure 4). This optimized package design of two perforations is the same condition obtained by Sousa-Gallagher and Mahajan [3] but gave a little difference in the equilibrated MA (4.8 and $19.8 \%$ of $\mathrm{O}_{2}$ and $\mathrm{CO}_{2}$ concentrations, resp., in the latter). Because the produce respiration and package gas permeability data used by them [3] may be different from ours, direct comparison of current outcome to the source is impossible. But the optimal MA conditions are found to be attained for strawberry with high respiration activity by microperforations in common plastic film. Presence of microperforations in permeable plastic package plays roles to increase gas transfer across the film layer and reduce the $\mathrm{CO}_{2} / \mathrm{O}_{2}$ permeability ratio near to 1 , which helps to design MAP for commodities 
TABLE 1: Commodity properties and package size for optimized MAP.

\begin{tabular}{|c|c|c|c|}
\hline \multirow{2}{*}{ Attribute } & \multicolumn{3}{|c|}{ MA requirements, respiration characteristics, and package dimension for commodity } \\
\hline & Green pepper & Strawberry & Mushroom-king oyster \\
\hline Optimum $\mathrm{O}_{2}(\%)$ & 4 & 7 & 1 \\
\hline Optimum $\mathrm{CO}_{2}(\%)$ & 5 & 18 & 10 \\
\hline $\mathrm{CO}_{2}$ tolerance limit $(\%)$ & 8 & 20 & 15 \\
\hline \multicolumn{4}{|l|}{ Parameters for $R_{\mathrm{O}_{2}}$} \\
\hline$V_{m}\left(\mathrm{~mol} \mathrm{~kg}^{-1} \mathrm{~h}^{-1}\right)$ & $1.70 \times 10^{-3}$ & $7.56 \times 10^{-4}$ & $6.37 \times 10^{-3}$ \\
\hline$K_{m}(\mathrm{kPa})$ & 6.03 & 0.02 & 1.78 \\
\hline$K_{i}(\mathrm{kPa})$ & 1.28 & 35.46 & 101.26 \\
\hline \multicolumn{4}{|l|}{ Parameters for $R_{\mathrm{CO}_{2}}$} \\
\hline$V_{m}\left(\mathrm{~mol} \mathrm{~kg}^{-1} \mathrm{~h}^{-1}\right)$ & $7.22 \times 10^{-4}$ & $7.56 \times 10^{-4}$ & $4.30 \times 10^{-3}$ \\
\hline$K_{m}(\mathrm{kPa})$ & 2.47 & 0.02 & 0.27 \\
\hline$K_{i}(\mathrm{kPa})$ & 4.40 & 81.04 & 20.29 \\
\hline Expected shelf life (h) & 300 & 240 & 360 \\
\hline Package type and dimension & Bag of $0.20 \times 0.15 \mathrm{~m}$ & Tray of $0.158 \times 0.09 \times 0.04 \mathrm{~m}$ & Bag of $0.22 \times 0.24 \mathrm{~m}$ \\
\hline Area for gas permeable surface $\left(\mathrm{m}^{2}\right)$ & 0.06 & $1.42 \times 10^{-2}$ & $1.06 \times 10^{-1}$ \\
\hline Fill weight (kg) & 0.11 & 0.20 & 0.25 \\
\hline Free volume $\left(\mathrm{m}^{3}\right)$ & $2.40 \times 10^{-4}$ & $3.69 \times 10^{-4}$ & $9.46 \times 10^{-4}$ \\
\hline
\end{tabular}

Respiration parameters for green pepper and strawberry are from literature sources $[9,10]$, and those for mushroom are determined by the closed system experiment.

TABLE 2: Output from optimized MAP design for the package sizes in Table 1.

\begin{tabular}{|c|c|c|c|}
\hline \multirow{2}{*}{ Output parameter } & \multicolumn{3}{|c|}{ Optimal package condition for commodity } \\
\hline & Green pepper & Strawberry & Mushroom-king oyster \\
\hline Permeable surface film and thickness (mm) & LDPE/0.042 & OPP/0.05 & $\mathrm{OPP} / 0.03$ \\
\hline Perforation diameter $(\mathrm{m})$ and number & None & $2.5 \times 10^{-4} / 2$ & $1 \times 10^{-4} / 17$ \\
\hline \multicolumn{4}{|l|}{$\mathrm{CO}_{2}$ scavenger $\left(\mathrm{Ca}(\mathrm{OH})_{2}\right)$} \\
\hline Weight $(\mathrm{g})$ & None & None & 9.5 \\
\hline Sachet film, thickness $(\mathrm{mm})$, and area $\left(\mathrm{m}^{2}\right)$ & & & LLDPE/0.020/0.065 or LLDPE/0.013/0.042 \\
\hline \multicolumn{4}{|l|}{ Equilibrated atmosphere } \\
\hline $\mathrm{O}_{2}(\%)$ & 4.0 & 9.3 & 1.1 \\
\hline $\mathrm{CO}_{2}(\%)$ & 5.1 & 17.5 & 10.0 \\
\hline
\end{tabular}

with recommended atmosphere of low $\mathrm{O}_{2}$ and high $\mathrm{CO}_{2}$ concentrations $[7,16]$.

3.3. Package of King Oyster Mushroom. Mushroom is of high respiration activity and highly perishable [14]. The respiration parameters of (1) for the optimization were determined by closed system method $[19,20]$, and high $V_{m}$ values represent high respiration rate of this commodity (Table 1). Optimal MA condition suggested for quality preservation varies with literatures or sources. In this study of MAP design, MA of $1 \%$ $\mathrm{O}_{2}$ and $10 \% \mathrm{CO}_{2}$, reported to be beneficial, was used as a target for the optimization $[21,22]$ (Table 1). The upper limit of $\mathrm{CO}_{2}$ concentration range $15 \%$ was adopted as the tolerance limit in the optimization. The outcome of design optimization showed the inclusion of 17 microperforations of $100 \mu \mathrm{m}$ on $0.03 \mathrm{~mm}$ thick OPP film and $\mathrm{CO}_{2}$ absorber of $9.5 \mathrm{~g} \mathrm{Ca}(\mathrm{OH})_{2}$ to attain the desired MA (Table 2). Different conditions of $\mathrm{CO}_{2}$ sachet film could be selected to give the same resultant

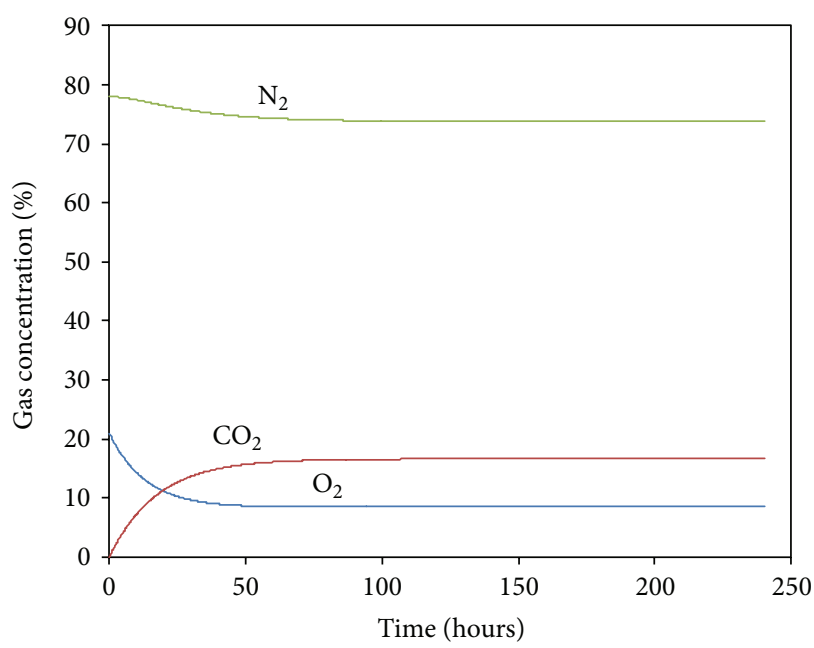

FIGURE 4: Optimal MA profile for strawberry package with requirements and design conditions in Tables 1 and 2. 


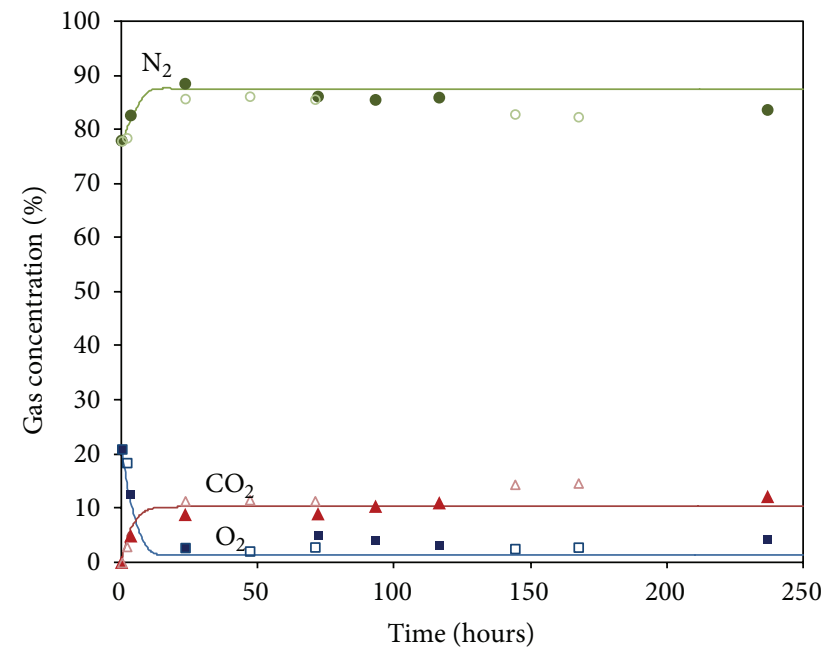

FIGURE 5: Optimal MA profile for king oyster mushroom package with requirements and design conditions in Tables 1 and 2. Open and close symbols are experimental gas concentration data obtained in two separate trials with LLDPE $\mathrm{CO}_{2}$ sachet film of 0.020 and $0.013 \mathrm{~mm}$, respectively.

equilibrium package atmosphere and two film thicknesses were given in Table 2 for later experimental testing. Apparently the high respiration activity of respiration seemed to need high number of microperforations to meet the $\mathrm{O}_{2}$ concentration of $1 \%$, but the presence of microperforations was not enough to maintain $\mathrm{CO}_{2}$ concentration below $15 \%$. Thus, the package design required $\mathrm{CO}_{2}$ absorber to let the $\mathrm{CO}_{2}$ concentration stay exactly at the optimal level of $10 \%$ according to (17) (Table 2). The simulation outcome of differential equations (3)-(5) in Figure 5 is nearly the same with package atmosphere from the equilibrated relationships in Table 2.

As a further way to validate the design method, the optimized package of mushroom was prepared and measured in its atmosphere during storage at $10^{\circ} \mathrm{C} . \mathrm{O}_{2}, \mathrm{CO}_{2}$, and $\mathrm{N}_{2}$ concentrations of the package were measured for one milliliter of gas samples taken through a silicon-sampling port by using a gas-tight syringe. Varian Model 3800 Gas Chromatography (Varian Inc., Palo Alto, CA, USA) equipped with an Alltech CTR I Column (Alltech Associates Inc., Deerfield, IL, USA) and a thermal conductivity detector was used for the gas analysis. The experimental package atmospheres tried with two different $\mathrm{CO}_{2}$ sachet systems were in very close agreement with the estimated ones (Figure 5), verifying the validity of the MAP optimization method developed in this study.

\section{Conclusions}

MAP design optimization methodology capable of attaining the desired MA was developed to select the most appropriate film, microperforations, and/or $\mathrm{CO}_{2}$ scavenger. The optimization algorithm first selects the film and/or microperforations to have the target $\mathrm{O}_{2}$ concentration and then tunes the
$\mathrm{CO}_{2}$ concentration by $\mathrm{CO}_{2}$ absorber when it goes above its tolerance limit. The optimization method tested for three different commodities was shown to be effective to design the package and the results obtained were consistent with literature work and experimental atmosphere.

\section{Conflict of Interests}

The authors declare that there is no conflict of interests regarding the publication of this paper.

\section{Acknowledgment}

This study was supported by the R\&D Convergence Centre Support Program of the Ministry of Agriculture, Food and Rural Affairs, Korea (Project no. 710003-1).

\section{References}

[1] P. V. Mahajan, F. A. R. Oliveira, J. C. Montanez, and J. Frias, "Development of user-friendly software for design of modified atmosphere packaging for fresh and fresh-cut produce," Innovative Food Science and Emerging Technologies, vol. 8, no. 1, pp. 84-92, 2007.

[2] T. Cagnon, C. Guillaume, V. Guillard, and N. Gontard, "Nanostructuring and microstructuring of materials from a single agropolymer for sustainable MAP preservation of fresh food," Packaging Technology and Science, vol. 26, no. 3, pp. 137-148, 2013.

[3] M. J. Sousa-Gallagher and P. V. Mahajan, "Integrative mathematical modelling for MAP design of fresh-produce: theoretical analysis and experimental validation," Food Control, vol. 29, no. 2, pp. 444-450, 2013.

[4] T. Cagnon, A. Méry, P. Chalier, C. Guillaume, and N. Gontard, "Fresh food packaging design: a requirement driven approach applied to strawberries and agro-based materials," Innovative Food Science and Emerging Technologies, vol. 20, no. 1, pp. 288298, 2013.

[5] M. S. Aday and C. Caner, "The Applications of 'active packaging and chlorine dioxide' for extended shelf life of fresh strawberries," Packaging Technology and Science, vol. 24, no. 3, pp. 123136, 2011.

[6] D. S. Lee, P. E. Haggar, J. Lee, and K. L. Yam, "Model for fresh produce respiration in modified atmospheres based on principles of enzyme kinetics," Journal of Food Science, vol. 56, no. 6, pp. 1580-1585, 1991.

[7] K. L. Yam and D. S. Lee, "Design of modified atmosphere packaging for fresh produce," in Active Food Packaging, M. L. Rooney, Ed., pp. 55-73, Blackie Academic and Professional, London, UK, 1995.

[8] S. Mangaraj, T. K. Goswami, and P. V. Mahajan, "Applications of plastic films for modified atmosphere packaging of fruits and vegetables: a review," Food Engineering Reviews, vol. 1, no. 2, pp. 133-158, 2009.

[9] K. S. Lee, K. L. Woo, and D. S. Lee, "Modified atmosphere packaging for green chili peppers," Packaging Technology and Science, vol. 7, no. 1, pp. 51-58, 1994.

[10] P. Renault, M. Souty, and Y. Chambroy, "Gas exchange in modified atmosphere packaging. 1: a new theoretical approach for micro-perforated packs," International Journal of Food Science \& Technology, vol. 29, no. 4, pp. 365-378, 1994. 
[11] M.-J. Kwon, Y. H. Jo, D. S. An, and D. S. Lee, "Applicability of simplified simulation models for perforation-mediated modified atmosphere packaging of fresh produce," Mathematical Problems in Engineering, vol. 2013, Article ID 267629, 9 pages, 2013.

[12] G. L. Robertson, Food Packaging Principles and Practice, CRC Press, Boca Raton, Fla, USA, 2nd edition, 2006.

[13] R. J. Ashley, "Permeability and plastics packaging," in Polymer Permeability, pp. 269-308, Chapman \& Hall, London, UK, 1985.

[14] A. A. Kader and M. E. Saltveit, "Respiration and gas exchange," in Postharvest Physiology and Pathology of Vegetables, J. A. Bartz and J. K. Brecht, Eds., pp. 7-29, Marcel Dekker, New York, NY, USA, 2003.

[15] Sandhya, "Modified atmosphere packaging of fresh produce: current status and future needs," LWT: Food Science and Technology, vol. 43, no. 3, pp. 381-392, 2010.

[16] J. D. Mannapperuma and R. P. Singh, "Modeling of gas exchange in polymeric packages of fresh fruits and vegetables," in Minimal Processing of Foods and Process Optimization, R. P. Singh and and F. A. R. Oliveira, Eds., pp. 437-458, CRC Press, Boca Raton, Fla, USA, 1994.

[17] D. R. Paul and R. Clarke, "Modeling of modified atmosphere packaging based on designs with a membrane and perforations," Journal of Membrane Science, vol. 208, no. 1-2, pp. 269-283, 2002.

[18] Y. H. Jo, D. S. An, and D. S. Lee, "Gas composition of microperforated individual package in master packaging system of strawberries," Journal of Food, Agriculture \& Environment, vol. 11, no. 3-4, pp. 289-293, 2013.

[19] P. E. Haggar, D. S. Lee, and K. L. Yam, "Application of an enzyme kinetics based respiration model to closed system experiments for fresh produce," Journal of Food Process Engineering, vol. 15, no. 2, pp. 143-157, 1992.

[20] J. J. Lee and D. S. Lee, "A dynamic method for kinetic model of fresh produce respiration in modified atmosphere and its application to packaging of prepared vegetables," Foods and Biotechnology, vol. 5, no. 4, pp. 343-348, 1996.

[21] M. Jeong, D. S. An, S. J. Lee, and D. S. Lee, “The quality of king oyster mushrooms stored with a master packaging system consisting of inner individual packs and an outer liner bag to be dismantled at a retail display," Food Science and Technology Research, vol. 18, no. 4, pp. 535-541, 2012.

[22] K. S. Burton and R. V. Twyning, "Extending mushroom storagelife by combining modified atmosphere packaging and cooling," Acta Horticulturae, vol. 258, no. 1, pp. 565-571, 1989. 


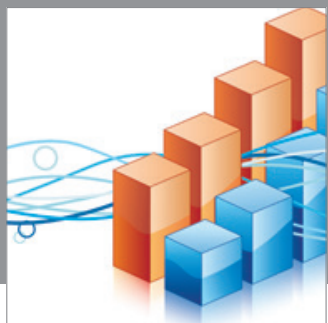

Advances in

Operations Research

mansans

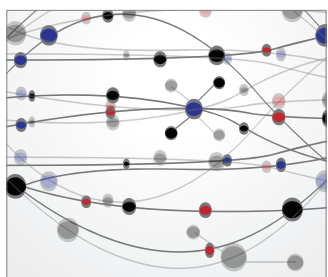

The Scientific World Journal
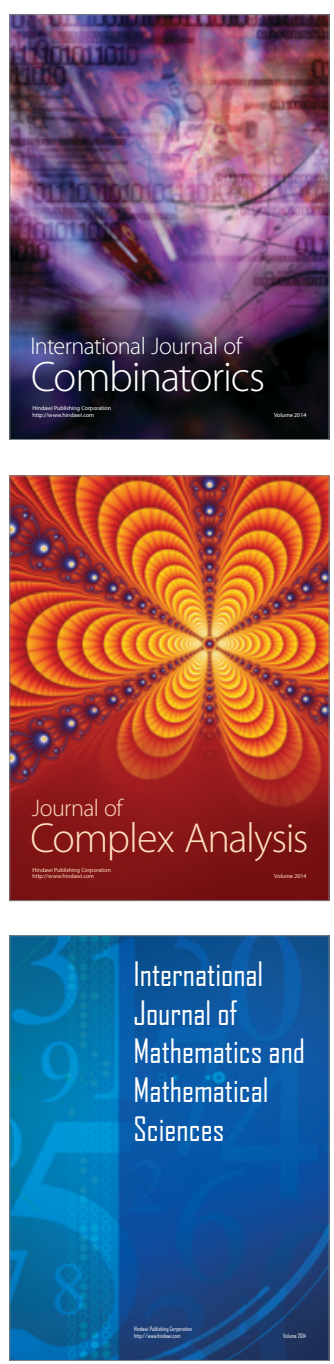
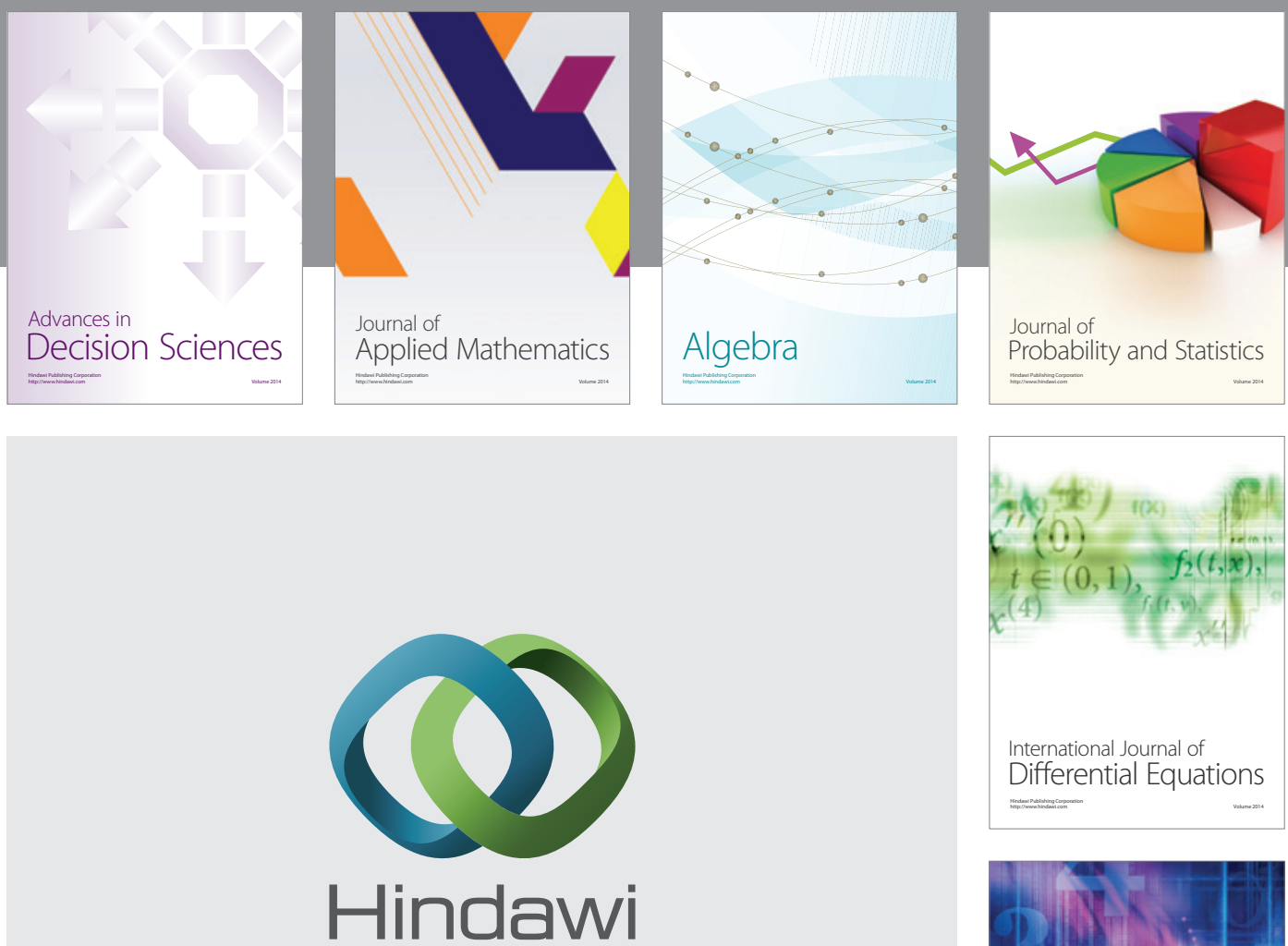

Submit your manuscripts at http://www.hindawi.com
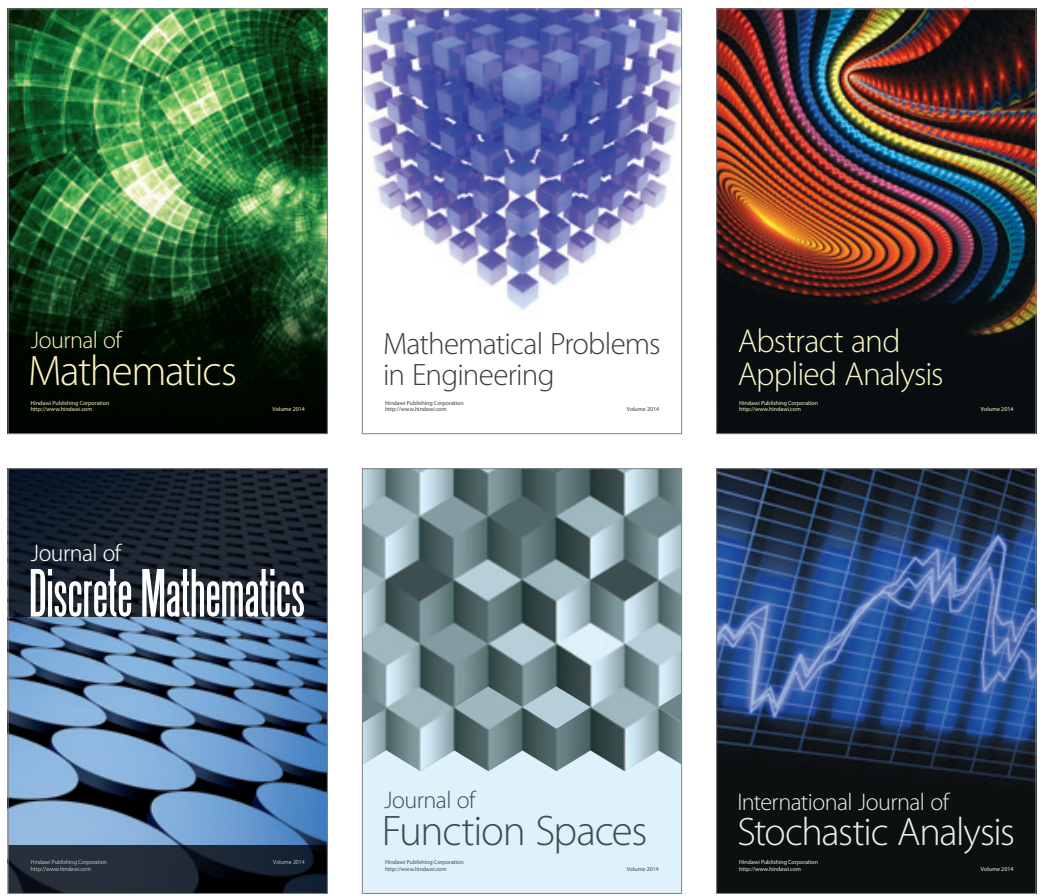

Journal of

Function Spaces

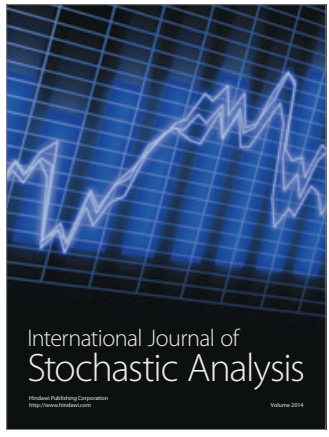

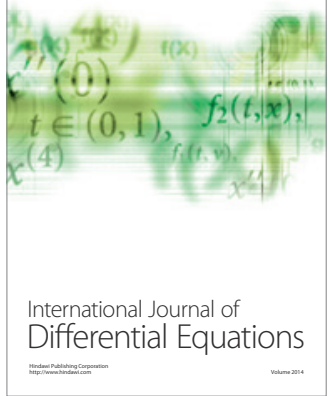
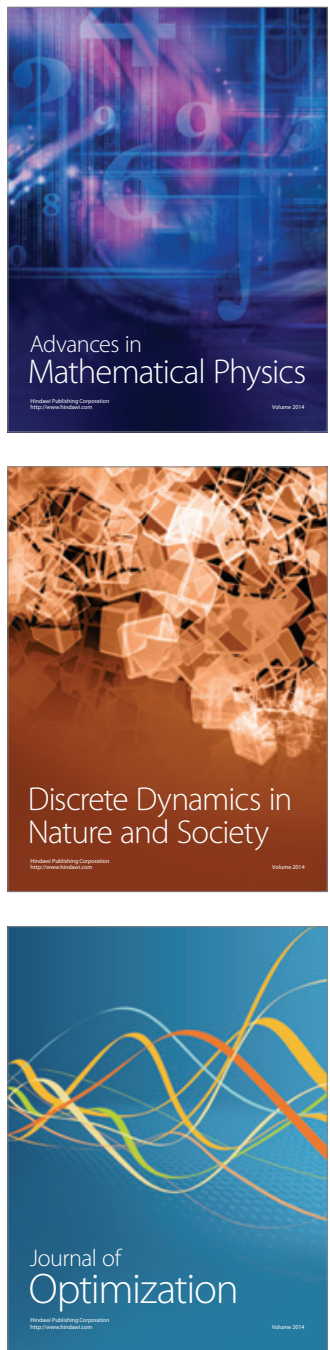